\title{
Study on sensitivity of annular BOP parameters to sealing performance in gas well snubbing service
}

\author{
Hai YANG*, Liangliang DONG**, XiangJun YU*, Yuan TANG**, Fang QIN*, Fangfang ZHANG* \\ and Jian TAN* \\ * Petro China Southwest Oil \& Gas Field Company \\ Chengdu, Sichuan 610051, PR China \\ E-mail: 201599010046@swpu.edu.cn \\ ** School of Mechatronic Engineering, Southwest Petroleum University \\ Chengdu, Sichuan 610500, PR China
}

Received: 15 December 2020; Revised: 20 January 2021; Accepted: 24 February 2021

\begin{abstract}
Annular Blowout Preventer (BOP) is the core device for snubbing service in gas wells. The wellhead can be sealed by operating the BOP. Rubber core of annular BOP is the main part of the sealing process, and its failure will cause blowout accidents and endanger the operators. Rubber core failure is mainly caused by the serious wear and fracturing damage, compared with oil well, during the snubbing service of the gas well, there is dry friction between rubber core and tubing, which is more prone to rubber core wear. Based on the Yeoh constitutive model, this paper fits the material parameters through the data measured by the rubber tensile experiment, and establishes the sealing performance evaluation model of the annular BOP based on the theory of rubber hyperelastic, large deformation theory and dynamic sealing theory. Meanwhile, compare it with the rubber core failure cases which used in field to verify the accuracy of the model. Based on these, this paper studies the influence of piston stroke, tubing size, friction coefficient between rubber core and tubing, rubber core attrition rate on sealing performance, and fitting the relationship between tubing size and piston stroke. The results show that: properly increasing the piston stroke by 2 to $3 \mathrm{~mm}$ will help to improve the sealing performance; when the tubing size is smaller, the rubber core is deformed too much while the seal process completed, which is easy to cause the rubber core to fracturing; friction coefficient between rubber core and tubing has no significant effect on static sealing performance; the friction coefficient less than 0.2 has little effect on the dynamic sealing performance; when the friction coefficient exceeds 0.4 , the dynamic sealing performance is reduced significantly; when the wear of rubber core is within $10 \mathrm{~mm}$, the sealing performance gradually decreases, but the sealing requirements can still be met. When it is more than $10 \mathrm{~mm}$, it cannot meet the sealing requirements of $35 \mathrm{MPa}$. The research work in this paper has certain guiding significance for the design, selection and use of the rubber core of annular BOP.
\end{abstract}

Keywords : Annular blowout preventer, Spherical rubber core, Large deformation of rubber, Numerical simulation, Sealing performance

\section{Introduction}

The snubbing service of gas well is an advanced downhole operation technology that maintains a certain pressure in the wellbore, lifting and lowering string under pressure and without pressure release. Compared with traditional, it can reduce the pollution to the pay zone, protect the original formation to the greatest extent, and improve the operating environment (Skogdalen et al., 2011). At the same time, it provides greater protection for the stable production in the middle and late stages of the oil and gas field. Its unique advantages have been generally accepted by the industry. The annular BOP is the main part of the snubbing service equipment for gas wells. It can control the wellhead sealing by extruding rubber core to complete the operation process. As the main component of BOP to seal the wellhead, the 
rubber core failure will cause blowout accidents easily and endanger the safety of the operators. The failure of the rubber core is mainly caused by the serious wear and fracturing damage. Therefore, many scholars analyzed the main failure reasons of the rubber core in combination with the theoretical derivation and failure rubber core which used in field, also have given a method to extend the service life. However, the analysis of the sealing performance of rubber core after abrasion is rarely mentioned. The sealing performance and service life of rubber core are related to the success of snubbing services in gas wells (Shafiee et al., 2020).

In recent years, many scholars have carried out a lot of research on the sealing process of the annular BOP in combination with the finite element method. Li et al. (Li et al., 2019) used a two-dimensional axisymmetric model in the finite element software to analyze the main pressure-bearing parts of the annular BOP, the top cover and the shell, found that there are two stress concentrations inside the shell, where are prone to failure, but the force of the rubber core was not analyzed. Zou et al. (Zou et al., 2016) assumed that both the BOP shell and the rubber core satisfy Hooke's law and did not consider the rubber core as a hyperelastic body. Numerical simulation were carried on the operation process of the annular BOP lifting and lowering the tubing, obtained the maximum stress of the shell and the rubber core when the BOP is working, which meets the sealing requirement. Chen et al. (Chen et al., 2019a) considered the rubber core as a hyperelastic body, but did not use the hyperelastic constitutive model in the process of analyzing the rubber core sealing tubing with the help of finite element software, obtained the relationship between rubber contact pressure and deformation, also calculated the residual life of the rubber through the dynamic fatigue curve. Mutlu et al. (Mutlu et al., 2018) analyzed the hydraulic sealing performance of annular BOP which used in deep water environments.

As the main sealing element in the sealing process, the safety and reliability of the rubber core in BOP is also valued by more and more scholars. Yao et al. (Yao et al., 2019) derived the deformation and contact pressure equations of the rubber core, which provided a theoretical basis for evaluation of the sealing performance of the annular BOP for snubbing service in gas-controlled gas wells. $\mathrm{Xu}$ et al. (Xu et al., 2012) obtained several main failure modes of the spherical rubber core through the mechanical analysis and field use of the spherical rubber core, gave a method to improve the reliability of the rubber core and prolong its life. $\mathrm{Xu}$ et al. (Xu et al., 2018) proposed a data processing method for the constitutive data of annular BOP with large deformation rubber core. Li (Li, 2015) analyzed the force and deformation regular pattern of rubber core under several typical working conditions, summarized the main failure modes of the rubber core, and gave a method to improve the sealing performance. Fu et al. (Fu et al., 2012) designed a new structure of rubber core in the ram BOP, which prolongs the service life of the rubber core. Chen et al. (Chen et al., 2019 b) verified that the critical area of the rubber matrix where is prone to cracks is consistent with the failure area of the rubber core used in the field through the crack initiation method.

In summary, many scholars have carried out research on the sealing process of the BOP and the design method of the spherical rubber core. However, there is little mention of the related research on the evaluation of the sealing performance of the spherical rubber core after abrasion. In this paper, combined with the structural symmetry characteristics of the BOP, a dynamic simulation analysis of 1/24 of the overall model of the BOP is carried out, which greatly reduces the amount of model calculation. At the same time, the Yeoh hyperelastic constitutive model is used to simulate the large deformation of rubber. Benefit from the less model calculations, this paper conducts multiple sets of simulation calculations on key factors such as piston stroke, tubing size, friction coefficient and abrasion, in order to study its influence on the sealing performance of the BOP. And also fits the relationship between tubing size and piston stroke. Provide a theoretical basis for the design and use of BOP rubber core for snubbing service in gas wells.

\section{Constitutive model and numerical model of rubber core}

\subsection{Constitutive parameters of rubber materials}

The research on hyperelastic models of rubber materials mainly includes molecular network models and phenomenological theoretical models. On the basis of the above two models, different constitutive models are derived by simplifying the model parameters. There are mainly Arrude-Boyce, Mooney-Rivlin, Yeoh, Ogden and other models (Charlton et al., 1994). Compared with other models, the Yeoh model is more suitable for describing large-deformation rubber materials (Gajewski et al., 2015; Renaud et al., 2009). The spherical rubber core of the BOP will be greatly deformed during the sealing process, so the rubber material adopts the Yeoh constitutive model in this paper.

Yeoh model assumes that the rubber material is isotropic and incompressible. Based on the stress-strain relationship, the constitutive relationship of the rubber material is established by the phenomenological theory. The 
strain energy density function $(W)$ can be expressed as (Yeoh, 1993):

$$
\begin{aligned}
& W=\sum_{i=1}^{N} C_{\mathrm{i} 0}\left(I_{1}-3\right)^{\mathrm{i}}+\sum_{k=1}^{N} \frac{1}{d_{k}}(J-1)^{2 \mathrm{k}}, \\
& I_{1}=\lambda_{1}^{2}+\lambda_{2}^{2}+\lambda_{3}^{2}, \\
& I_{2}=\lambda_{1}^{2} \lambda_{2}^{2}+\lambda_{2}^{2} \lambda_{3}^{2}+\lambda_{1}^{2} \lambda_{3}^{2}, \\
& I_{3}=\lambda_{1}^{2} \lambda_{2}^{2} \lambda_{3}^{2}=1, \\
& \lambda_{\mathrm{i}}=1+\gamma_{\mathrm{i}},
\end{aligned}
$$

where $N, d_{k}, C_{i 0}$ are the material constants; $I_{1}, I_{2}, I_{3}$ are the deformation tensor invariants; $\lambda_{1}, \lambda_{2}, \lambda_{3}$ are the main elongation ratios; $\gamma_{i}$ are the main strains.

For incompressible rubber materials, $J=1$. The Eq. (1) can be simplified as:

$$
W=\sum_{i=1}^{N} C_{i 0}\left(I_{1}-3\right)^{i}
$$

The commonly used three parameter expansions are as follows:

$$
W=C_{10}\left(I_{1}-3\right)+C_{20}\left(I_{1}-3\right)^{2}+C_{30}\left(I_{1}-3\right)^{3}
$$

The commonly used material for the rubber core is nitrile rubber. To determine the constitutive parameters of the rubber, make a standard sample of nitrile rubber according to Fig. 1(a), and use the universal testing machine shown in Fig. 1(b) to measure the dumbbell-shaped specimen is subjected to a uniaxial tensile test at a speed of $500 \mathrm{~mm} \pm 50$ $\mathrm{mm} / \mathrm{min}$ until the specimen is broken. The sample after breaking is shown in Fig. 1(c).

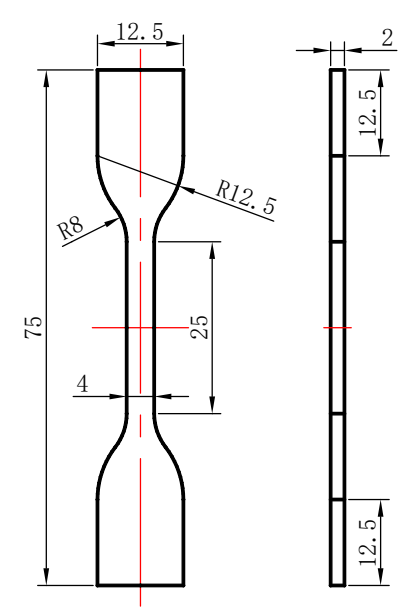

(a) Specimen size

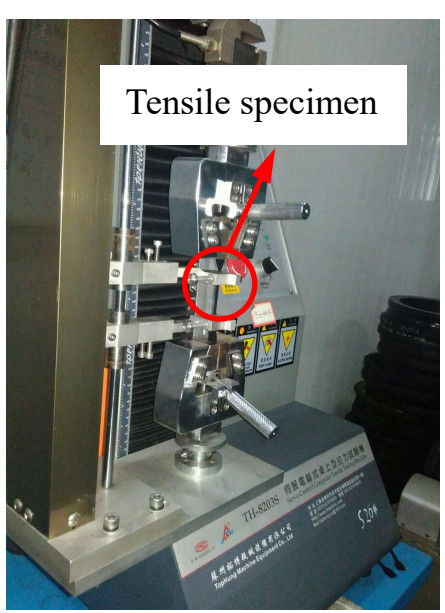

(b) Tensile test

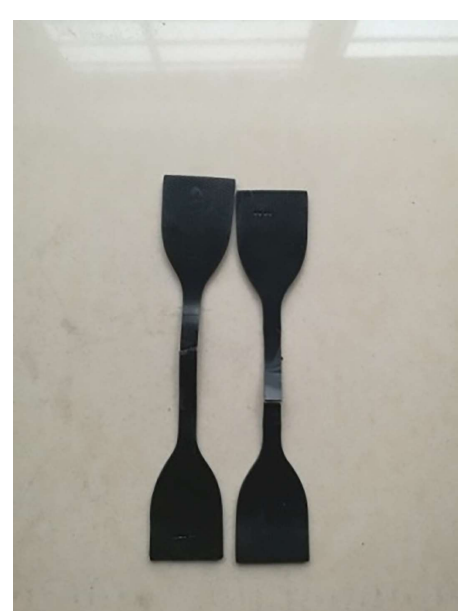

(c) Specimen after fracture

Fig. 1 Testing process

According to the theory of small deformation, when the material is stretched in the axial direction, it is assumed that the cross-sectional area of the sample unchanged or changes very little, which can be ignored. Therefore, when the sample is stretched, its tensile stress $(\sigma)$ and tensile strain $(\varepsilon)$ can be calculated according to Eq. (8) and Eq. (9): 


$$
\begin{gathered}
\sigma=\frac{P}{S_{0}}, \\
\varepsilon=\frac{\Delta L}{L_{0}},
\end{gathered}
$$

where $P$ is the axial tensile load applied to the sample, $S_{0}$ is the original cross-sectional area of the sample, $\Delta L$ is the axial tensile deformation of the sample, and $L_{0}$ is the original axial length of the sample. Combining Eq. (8) and Eq. (9), the uniaxial tensile test data is processed to obtain multiple sets of stress-strain data, as shown in Fig. 2(a).

Figure 2(b) shows the final stress-strain data obtained after averaging the experimental data (As shown in Fig. 2(a)) and the constitutive parameter curve of the Yeoh constitutive model fitted by this stress-strain data.
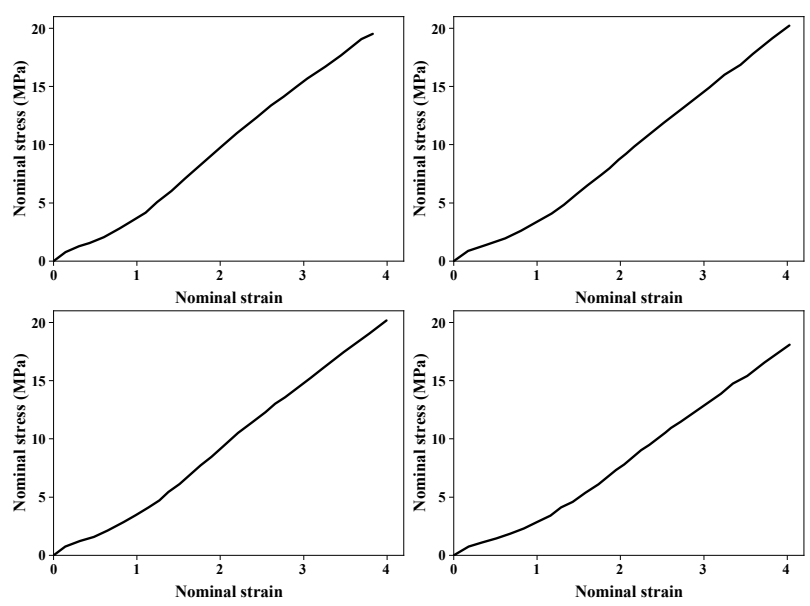

(a) Four groups of stress-strain data were obtained by tensile test

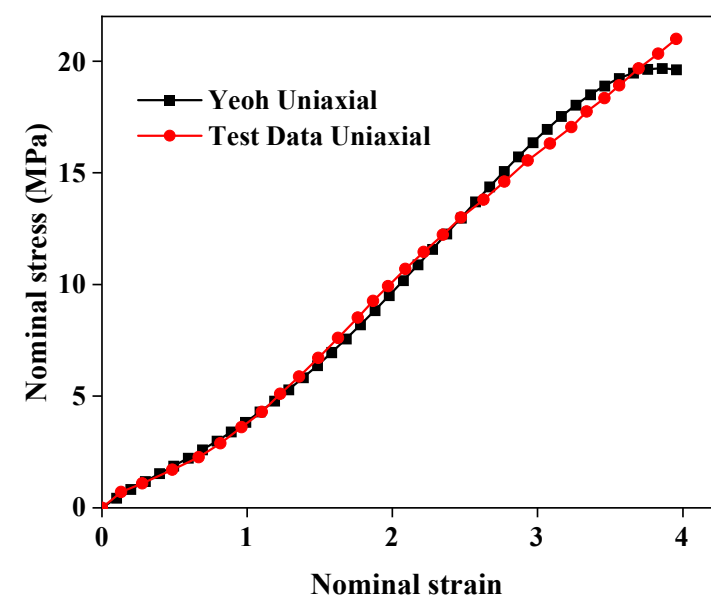

(b) Take the average value of the four groups of experimental data shown in Fig. 2 (a) to fit the constitutive model of rubber core material

Fig. 2 Stress-strain curve

\subsection{Geometric model}

Figure 3(a) shows the three-dimensional structure of the annular BOP. Since the geometry, boundary conditions and loads of the model meet the requirements of the rotating periodic structure (Abaqus Analysis User's Guide, Version 2016), only 1/24 of the model is used for calculation (Ferreira et al., 2003; Medri and Strozzi, 1984). The simplified model is shown in Fig. 3(b). In the model as shown in Fig. 3(b), the hardness difference between rubber and other metal structural parts is large, so rigid body constraints are imposed on all non-rubber parts. The rubber material parameters are fitted with experimental data. Since rubber is a super elastic material, the option Nlgeom needs to be set to On.

All the mesh element types of the model adopt the hexahedral mesh element type C3D8R which is commonly used in ABAQUS software. The rubber core is the main force analysis object. When dividing the grid, the global grid size is set to 3 , and the size of the remaining metal structures is set to 8 . Table 1 shows the setting of boundary conditions for key parts of the model. Among them, local coordinate systems are established on the $0^{\circ}$ and $15^{\circ}$ planes to facilitate the setting of symmetrical boundary conditions. Due to the large amount of movement between components, in order to facilitate calculation convergence, the calculation process adopts Dynamic Explicit. 
Table 1 Boundary conditions of key parts of the model

\begin{tabular}{c|c}
\hline \hline Part name & Boundary conditions \\
\hline The faces of $0^{\circ}$ and $15^{\circ}$ & Symmetry \\
\hline Top cover & Fixed \\
\hline Piston & Vertical upward displacement $80 \mathrm{~mm}$ \\
\hline tube & Fixed \\
\hline
\end{tabular}

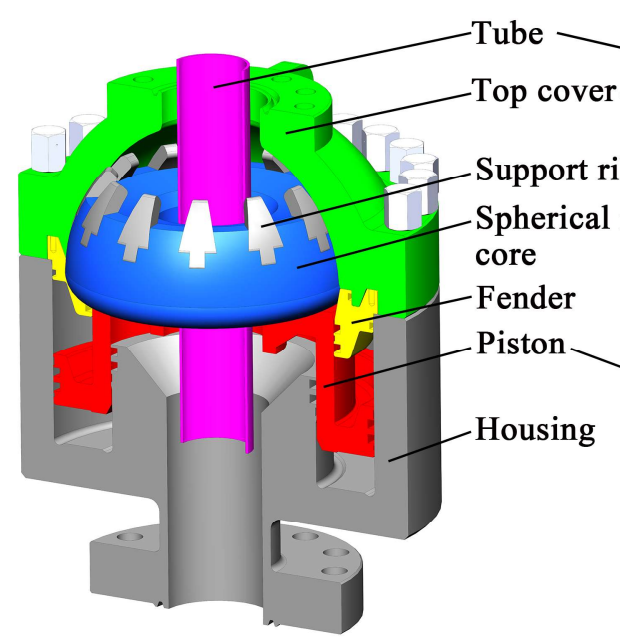

(a) 


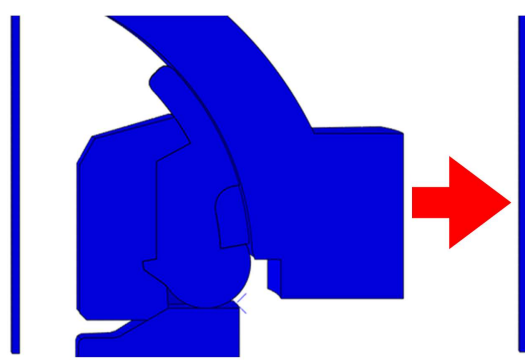

(a) $0 \mathrm{~mm}$

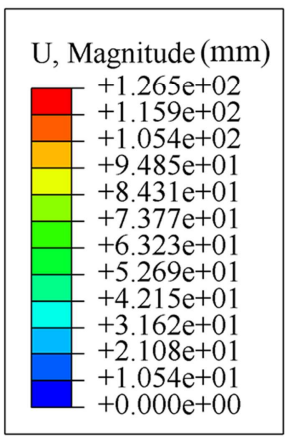

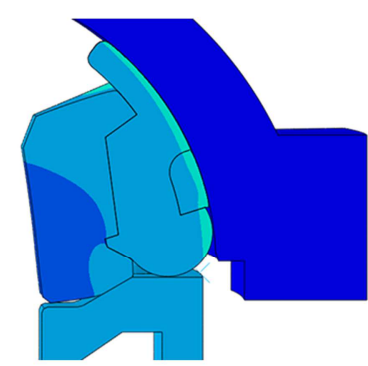

(b) $27 \mathrm{~mm}$

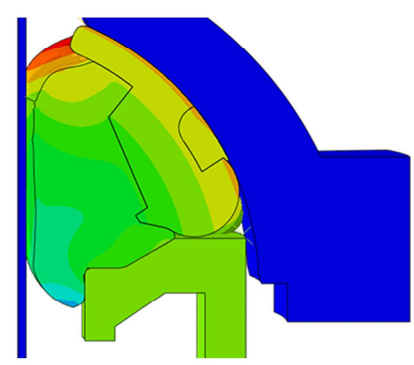

(e) $80 \mathrm{~mm}$

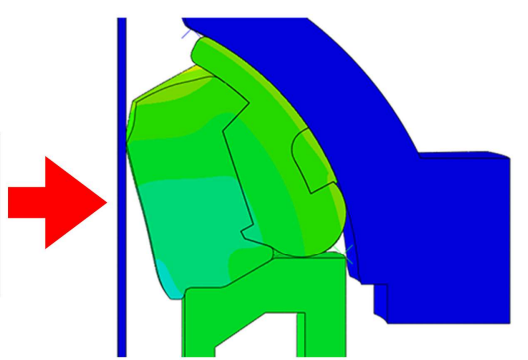

(c) $63 \mathrm{~mm}$

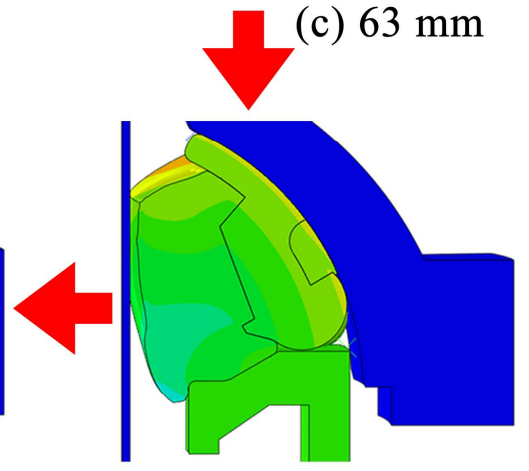

(d) $71 \mathrm{~mm}$

Fig. 4 The BOP finished a complete sealing process as the piston stroke increases

\subsection{Analysis of sealing performance in sealing process}

\subsubsection{The influence of piston stroke on rubber core stress}

The annular BOP will cause rubber core to fail during use. This is because when the rubber is deformed greatly, the tensile or compressive stress exceeds the allowable value of the rubber, it will cause rubber cracking, tearing, etc. (Volokh, 2010, 2013). Rubber core failure often occurs at the place where the stress concentration is greatest, and the stroke of piston is an important factor affecting the rubber core stress. In order to study the influence of stroke on rubber core stress, different strokes are calculated. According to the calculation results, when the stroke is $71 \mathrm{~mm}$, rubber core and tubing begin to contact. As the stroke increases, the rubber core's extrusion to the tubing gradually increases. When the stroke increases to $86 \mathrm{~mm}$, rubber core and tubing are in full contact with each other, meanwhile, the rubber core has been deformed very seriously.

Figure 5 shows the calculation results when the stroke of piston is $74 \mathrm{~mm}, 80 \mathrm{~mm}$, and $86 \mathrm{~mm}$. When the stroke increases from $74 \mathrm{~mm}$ to $86 \mathrm{~mm}$, the deformation of rubber increases and also the maximum stress. The area of stress concentration mainly at the contact part between the upper part of rubber core and the supporting rib (Fig. 5(c)Q), and the part where the lower part contacts the piston (Fig. 5(c)W). It can be concluded that during the shut-in process of the annular BOP, with the increase of the stroke, the stress concentration of rubber core increases at the positions of $\mathrm{Q}$ and $\mathrm{W}$, which eventually causes the rubber core to fracture. Figure 6 shows the rubber core after several experiments on site, and the cracking of the rubber can be seen clearly. The ductile fracture location is shown in Fig. 5 at the stress concentration location $(\mathrm{Q}, \mathrm{W})$.

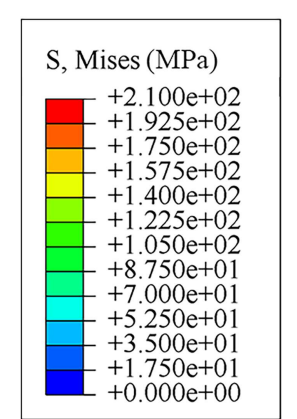

(a) $74 \mathrm{~mm}$

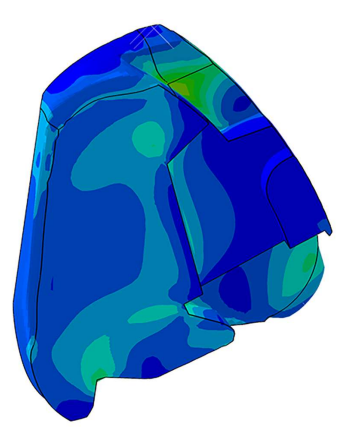

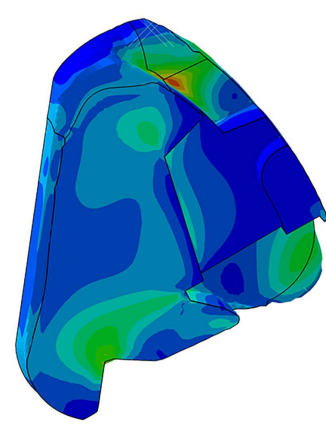

(b) $80 \mathrm{~mm}$

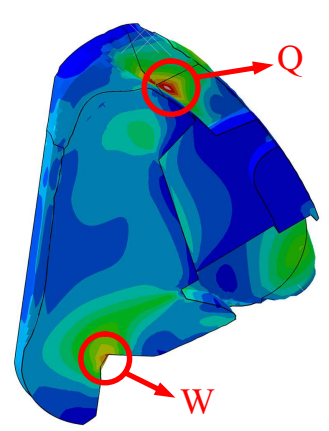

(c) $86 \mathrm{~mm}$

Fig. 5 Stress of rubber core when BOP completes sealing under different piston stroke 


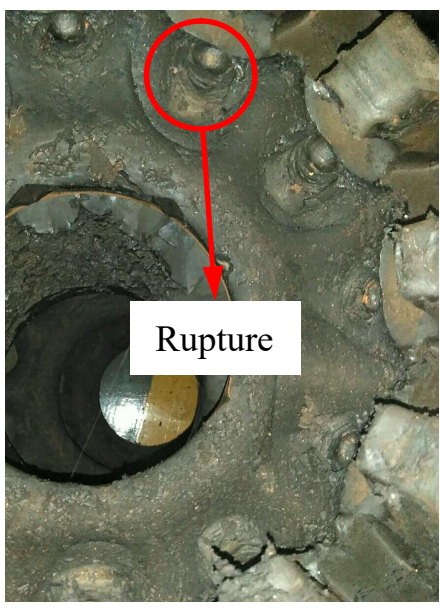

(a) The upper part of the rubber core ruptured (as shown in Fig. 5 (c) Q)

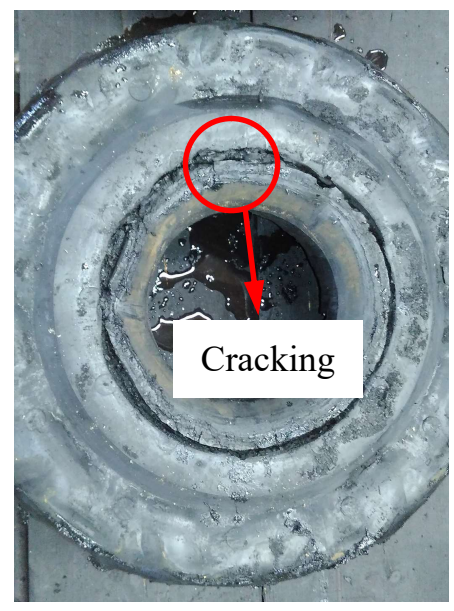

(b) The lower part of the rubber core cracked where in contact with the piston (as shown in Fig. 5 (c) W)

Fig. 6 Rubber core failure case

\subsubsection{Influence of stroke on sealing performance}

Evaluation of rubber sealing performance mainly based on whether the contact stress between rubber and casing exceeds the working pressure in the wellbore (Dong et al., 2020). In the process of sealing the wellhead annulus by the BOP, the rubber core shrinks toward the spherical center to squeeze the tubing to achieve sealing. When the sealing pressure between the rubber core and the tubing, that is, the contact pressure, exceeds the pressure of the fluid in the wellhead annulus, the BOP can be considered to be sealed.

In order to study the influence of piston stroke on sealing performance, the contact stress of rubber core under the stroke of 71 86 $\mathrm{mm}$ is calculated. Figure 7 shows the contact stress distribution on the contact surface between rubber core and tubing when the piston stroke is $74 \mathrm{~mm}, 80 \mathrm{~mm}$, and $86 \mathrm{~mm}$ (the surface where the K path is shown in Figure 8(a)). Extract the contact stress in the K path on the contact surface between rubber core and tubing, as shown in Fig. 8(b).

According to the calculation result as shown in Fig. 7(b), when the piston stroke is $71 \mathrm{~mm}$, the contact stress in part of the contact area exceeds $35 \mathrm{MPa}$. At this time, the sealing conditions are satisfied. But the contact area between rubber core and tubing is too small, which easily leads to sealing performance insufficient. When the stroke is $80 \mathrm{~mm}$, it can be seen that all the contact stress has exceeded $35 \mathrm{MPa}$, and the wellhead can be sealed stably. When the stroke is $86 \mathrm{~mm}$, the contact stress far exceeds the wellbore pressure by $35 \mathrm{MPa}$, and sealing can be satisfied. However, due to the severe extrusion, it is easy to cause the rubber core to fracture. When the piston stroke is $80 \mathrm{~mm}$, rubber core can seal the wellhead while ensuring that contact stress between the rubber core and the tubing is relatively small. It can be concluded that when sealing tubing with an outer diameter of $88.9 \mathrm{~mm}$, a piston stroke of $80 \mathrm{~mm}$ is more appropriate.

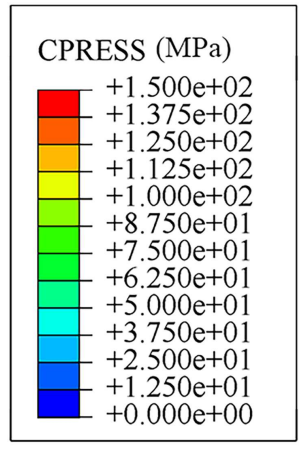

(a) $74 \mathrm{~mm}$

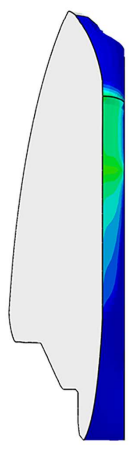

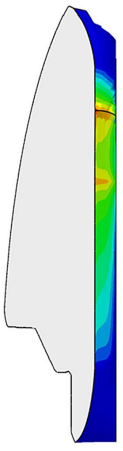

(b) $80 \mathrm{~mm}$

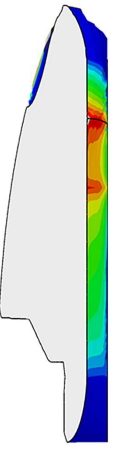

(c) $86 \mathrm{~mm}$

Fig. 7 Contact stress between rubber core and tubing when BOP completes sealing under different piston stroke 


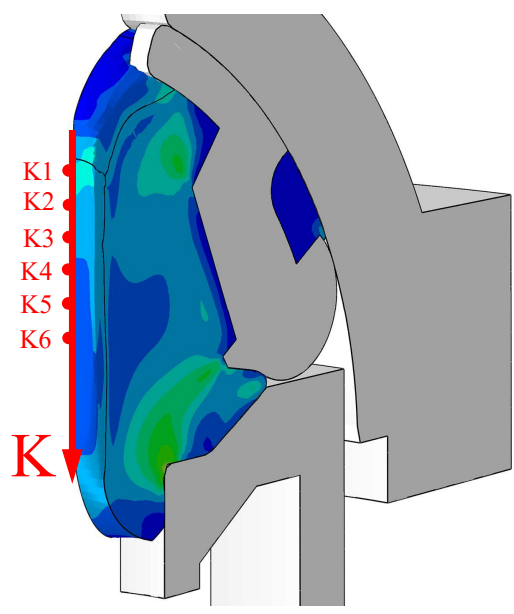

(a) K path

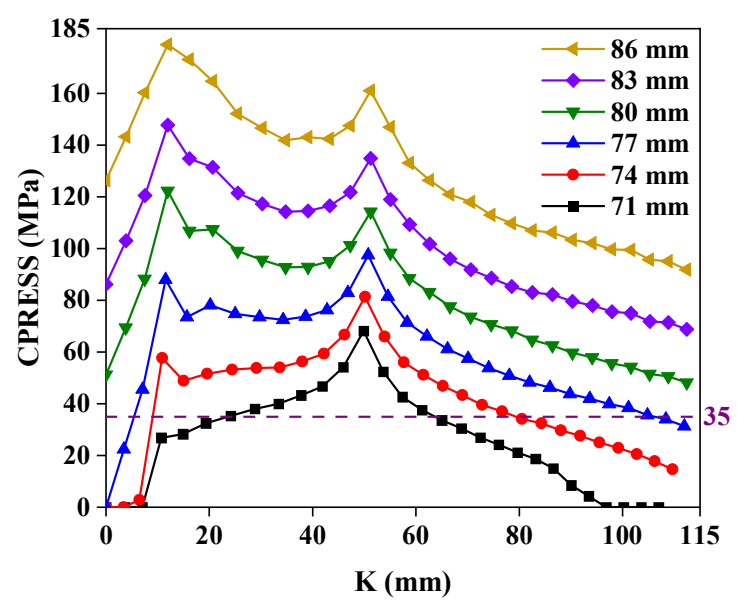

(b) Contact stress of rubber core along $\mathrm{K}$ path when BOP completes sealing under different piston stroke Fig. $8 \mathrm{~K}$ path contact stress

\section{Adaptability analysis of tubing size}

\subsection{Relationship between sealing performance and tubing size}

\subsubsection{Influence on rubber core stress}

Annular BOP can seal the annular space formed between tubing of different sizes and the wellbore. The size of tubing is different, also the deformation of rubber core during sealing. In order to study the influence of the stress in rubber core when it is sealed under different sizes of tubing, numerical simulation were carried out on different sizes of tubing between 60 and $100 \mathrm{~mm}$. Fig. 9 shows the calculation results of three commonly used tubing sizes in engineering. The results shown in Fig. 9 show that when the tubing size is smaller, the deformation of rubber core is relatively large after sealing the wellhead. At the same time, the stress of the upper part of rubber core in contact with the supporting ribs (Fig. 9(c)X) and the lower part in contact with the piston (Fig. 9(c)Y) increase as the size of the tubing decreases. Therefore, in the process of increasing the piston stroke to seal the wellhead annulus, the BOP will cause the fracture of the rubber at the $\mathrm{X}$ and $\mathrm{Y}$ positions.

Table 2 shows the maximum stress of rubber core when the seal is completed under different tubing outer diameter sizes, and the increase compared with the maximum stress when the $88.9 \mathrm{~mm}$ tubing outer diameter is sealed. It can be seen from Table 2 that as the outer diameter of tubing decreases, the maximum stress of rubber core increases step by step. When the outer diameter of tubing was reduced from $88.9 \mathrm{~mm}$ to $60.3 \mathrm{~mm}$, the maximum stress of rubber core increased by $36.4 \%$. It can be seen that the larger the annular space formed between tubing and wellbore, that is, the smaller the tubing size, the greater stress concentration and damage in the rubber core when the BOP is sealed.

Table 2 Maximum stress and increment of rubber core when BOP seals annulus formed by different sizes of tubing and wellbore

\begin{tabular}{|c|c|c|}
\hline Out diameter of tubing $(\mathrm{mm})$ & $\begin{array}{c}\text { Maximum stress of rubber } \\
\text { core }(\mathrm{MPa})\end{array}$ & Increment $(\%)$ \\
\hline 88.9 & 173 & \\
\hline 73 & 200 & 15.6 \\
\hline 60.3 & 236 & 36.4 \\
\hline
\end{tabular}



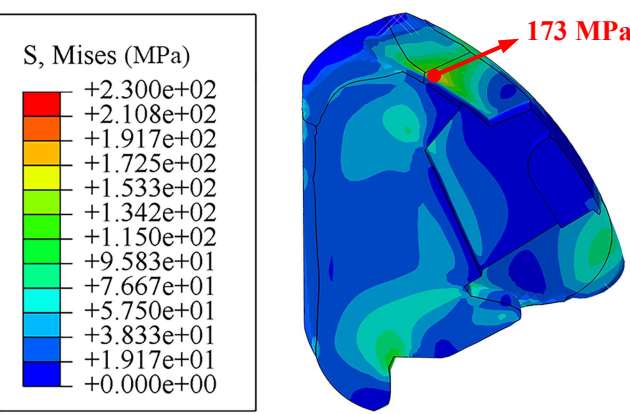

(a) $88.9 \mathrm{~mm}$

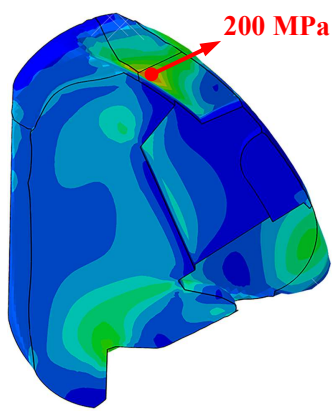

(b) $73 \mathrm{~mm}$

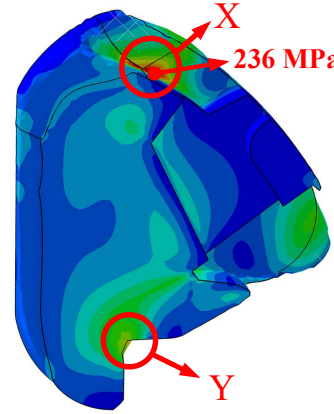

(c) $60.3 \mathrm{~mm}$

Fig. 9 Stress of rubber core when BOP seals annulus formed by different sizes of tubing and wellbore

\subsubsection{Influence on contact stress of rubber core}

In order to study the contact stress distribution in rubber core and tubing contact surface when the annular BOP seals the wellhead under different tubing outer diameters, Fig. 10 shows the contact stress between rubber core and tubing when BOP is sealed under various tubing sizes. It can be seen from Fig. 10 that when the BOP is sealed, the contact stress distribution between rubber core and tubing is basically the same. Fig. 11 shows the contact stress distribution curve of rubber core along the $\mathrm{K}$ path when the BOP is sealed. It can be seen from Fig. 11 that when the BOP finished sealing of the three tubing with different outer diameters, the changes of the contact stress is basically the same. The reason for this phenomenon is that the contact stress between rubber core and tubing must be greater than the wellbore annulus pressure when the BOP completes the seal. The annulus pressure is constant, and the rubber core deforms consistent during the sealing process. So, when the piston stroke is increased to complete the seal, the contact stress variety between rubber core and tubing is also consistent. Therefore, the outer diameter of the tubing has little effect on the contact stress between rubber core and tubing when the BOP seals the wellhead annulus.

Consequently, the annular BOP can be operated under different sizes of tubing. However, the smaller the tubing size, the greater stress concentration of rubber core after the sealing is completed, also the greater damage to rubber core. When BOP is sealed under different outer diameter tubing, the contact stress distribution of rubber core is roughly the same.

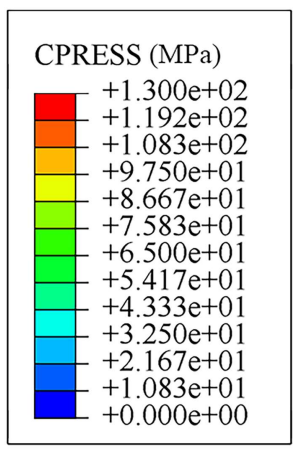

(a) $88.9 \mathrm{~mm}$

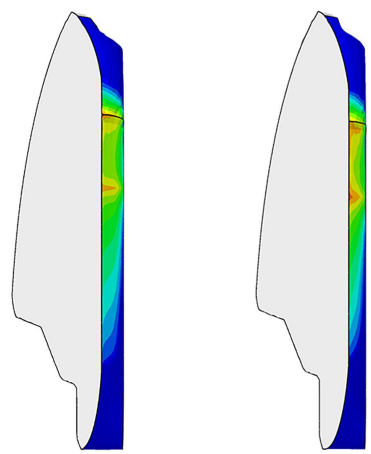

(b) $73 \mathrm{~mm}$

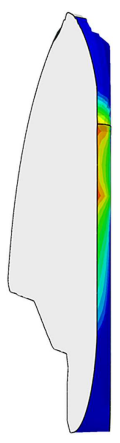

(c) $60.3 \mathrm{~mm}$

Fig. 10 Contact stress of rubber core when BOP seals annulus formed by different sizes of tubing and wellbore 


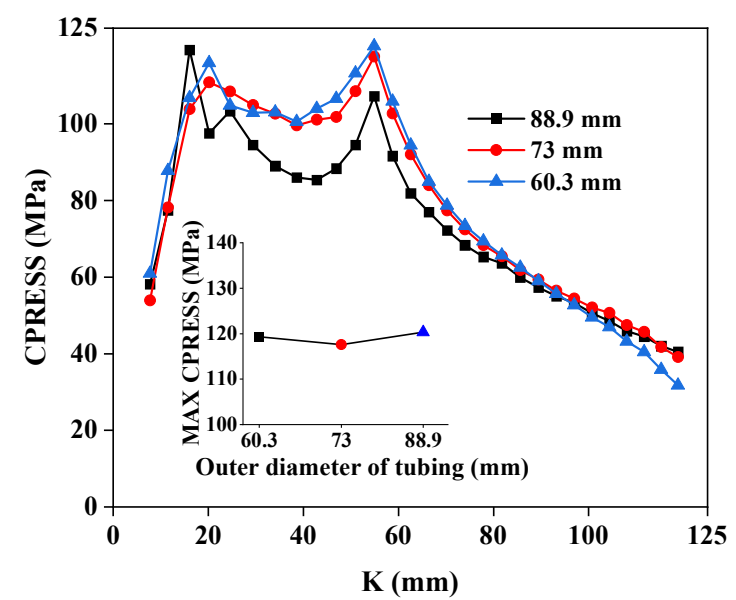

Fig. 11 Contact stress distribution of rubber core when BOP seals annulus formed by different sizes of tubing and wellbore

\subsection{Tubing size-piston stroke association relation}

By calculating the required piston stroke of seal the tubing with the outer diameter between 60 and $100 \mathrm{~mm}$, the tubing size-piston stroke curve is fitted, and the correlation equation is obtained, as shown in Eq. (10). Fig. 12 shows the results of numerical analysis and the curve obtained after software fitting. From the results shown in Fig. 12, it can be seen that both R-Square (Coefficient of Determination) and Adj. R-Square are above 0.99, which shows that the curve after fitting is in good coincidence with the original data curve. The equation of the curve fitted by software is:

$$
y=-0.0029 x^{2}+0.156 x+88.54
$$

where $x$ is the outer diameter of tubing; $y$ is the piston stroke.

Through this equation, it is theoretically possible to calculate the piston stroke required by the tubing with the outer diameter of the BOP seal between 60 and $100 \mathrm{~mm}$.

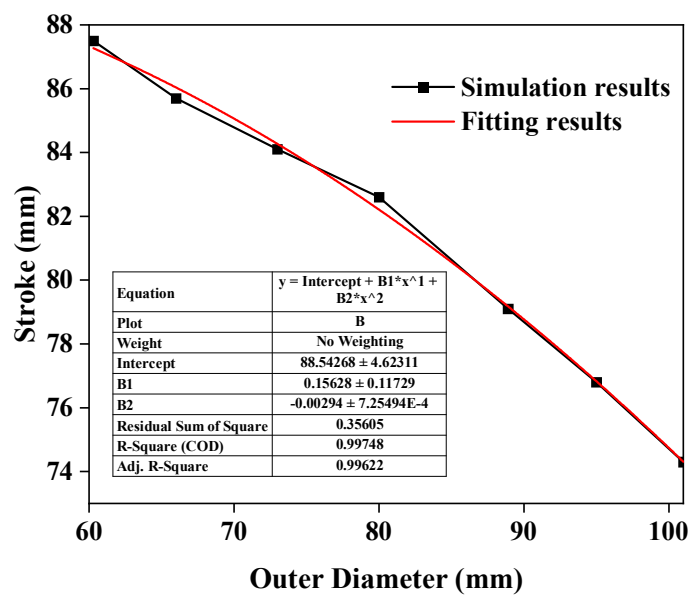

Fig. 12 Calculation result and fitted curve

\subsection{The effect of friction coefficient on sealing performance}

In the actual working conditions of the snubbing service of a gas well, the coefficient of friction between rubber core and tubing will vary with external factors such as the different lubrication levels between rubber core and tubing, also the temperature of the operating environment. The contact between rubber and metal is non-penetration constraint, so the friction type between the rubber core and the tubing is set as friction in the form of a penalty function. In order to study the effect of different friction coefficients on the maximum stress and contact stress of the rubber core at the completion of the seal, the outer diameter of the tubing is $88.9 \mathrm{~mm}$ and the piston stroke is $80 \mathrm{~mm}$ as an example, set 6 
different friction coefficients respectively, calculate the change of contact stress between rubber core and tubing under different friction coefficients, to judge the sealing performance of the BOP.

\subsubsection{Analysis of the influence of friction coefficient on static seal}

Fig. 13 shows the contact stress between rubber core and tubing along the $\mathrm{K}$ path when the BOP is sealed under various friction coefficients. It can be seen from Fig. 13 that when the friction coefficient changes between 0.08 and 1.0 , the contact stress is basically unchanged after the sealing is completed, and the maximum contact stress changes is low. This is because when the BOP is sealed, there is no relative movement between tubing and rubber core, and no friction was generated, so the friction coefficient has no effect on the contact stress. Thus, the friction coefficient almost has no effect on the sealing performance between rubber core and tubing when the wellhead annulus is sealed.

Fig. 14 shows the maximum stress of rubber core when the BOP is sealed under various friction coefficients. It can be seen from Fig. 14 that when BOP completes the sealing under various friction coefficients, the maximum stress value of rubber core changes is low. Only when the friction coefficient is 0.6 , there is a small fluctuation. And compared with other friction coefficients, the maximum stress of rubber core increased by about $10 \mathrm{MPa}$. But overall, the friction coefficient has little effect on the maximum stress of rubber core. Therefore, when annular BOP seals the wellhead and the tubing is stationary, the friction coefficient has no significant effect on the sealing performance of the BOP.

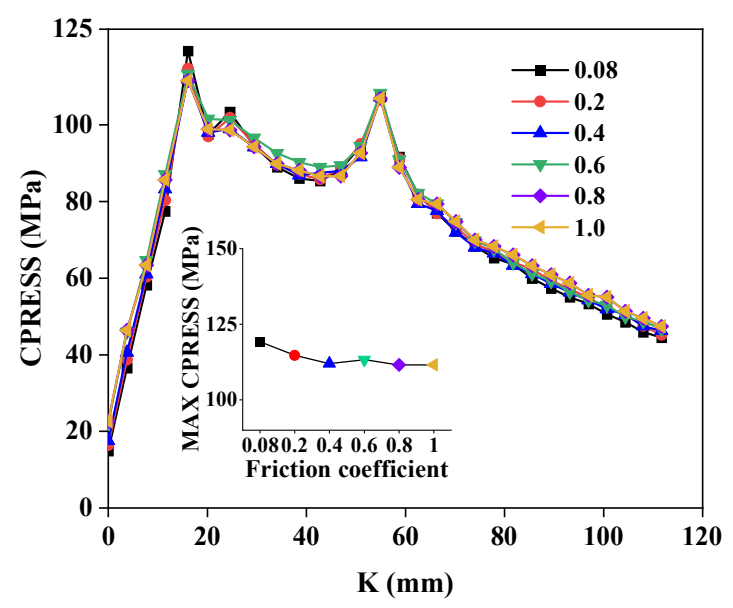

Fig. 13 Contact stress along k-path between rubber core and tubing when BOP seals wellhead annulus under different friction coefficient between rubber core and tubing

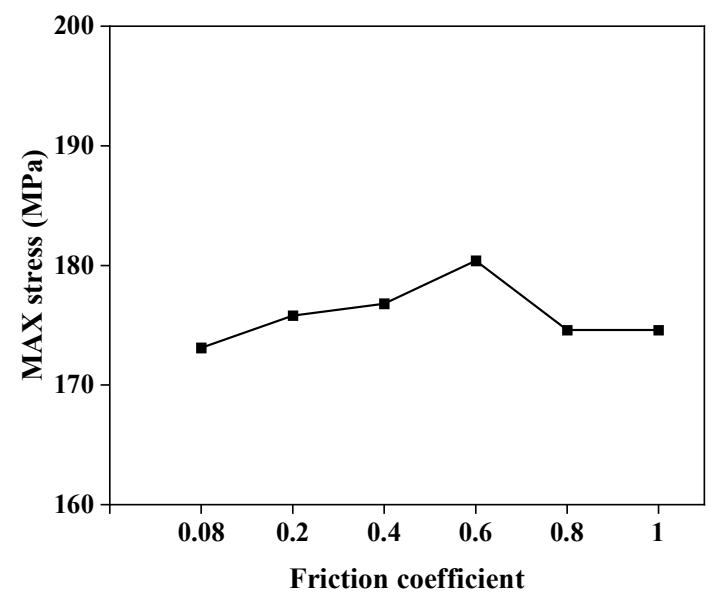

Fig. 14. The maximum stress of rubber core of BOP sealing wellhead annulus under different friction coefficient between rubber core and tubing

\subsubsection{Analysis of the influence of friction coefficient on dynamic seal}

After the BOP is sealed, in the process of lifting and lowering the tubing, the friction force on the contact surface between the rubber core and the tubing will affect the sealing performance of the BOP. In order to study the influence of friction coefficient on the contact pressure of rubber core when the tube is moving, after the sealing process is completed, with the help of the restart function of ABAQUS software, the displacement boundary conditions are set to make the tubing move down, and the 6 nodes on the $\mathrm{K}$ path are selected, namely $\mathrm{k} 1, \mathrm{k} 2, \mathrm{k} 3, \mathrm{k} 4, \mathrm{k} 5$, $\mathrm{k} 6$. The contact pressure under different friction coefficient is calculated, and its curve is drawn, as shown in Fig. 15.

Figure 15 show that when the friction coefficient is less than 0.2 , although the rubber core contact stress fluctuates slightly during the tubing movement, the overall value is still higher than $35 \mathrm{MPa}$, which means that it has no significant effect on the sealing performance. Among them, the point $\mathrm{k} 1$, as the maximum value of the contact stress, changes slightly in the entire process of tubing movement compared to other points. This is because the greater the contact stress, the greater the friction force corresponding to the point, and the tubing moves with the rubber core. The greater interaction force between them, the greater magnitude of the change in contact stress. When the friction coefficient is 0.4 or more, the contact stress of multiple points such as $\mathrm{k} 1$ and $\mathrm{k} 2$ fluctuates greatly, and the negative contact stress even appears at the $\mathrm{k} 1$ point. When the friction coefficient is 0.6 and 0.8 , the amplitude of contact stress 
fluctuates more drastically. At this time, the sealing performance will drop sharply. The reason for this phenomenon is that the friction force between rubber core and tubing increases with the increase of the friction coefficient. Violent stick-slip motion occurs between tubing and rubber core. As a result, the contact stress of the rubber core fluctuates greatly, which affects the sealing performance.

It can be concluded that when the tubing moves and the friction coefficient is below 0.2 , it has no obvious effect on the sealing performance. When the friction coefficient is greater than 0.4 , tubing movement will cause the performance of BOP to decrease. In actual operation, the tubing and rubber core should be fully lubricated to reduce the friction coefficient and improve the dynamic sealing performance of the BOP.

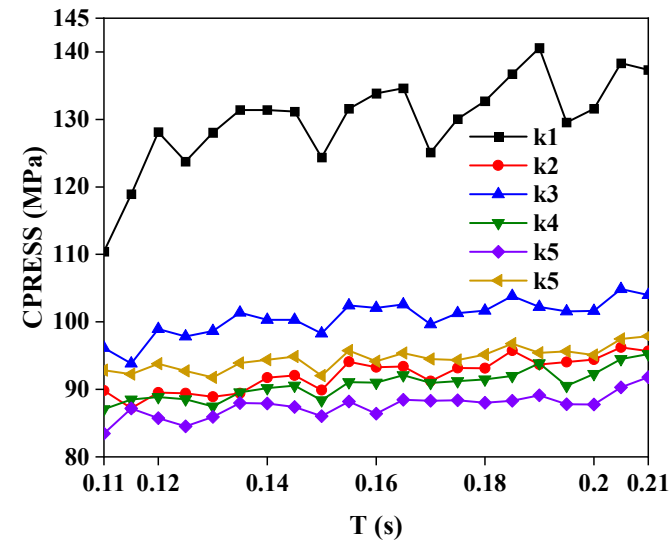

(a) 0.06

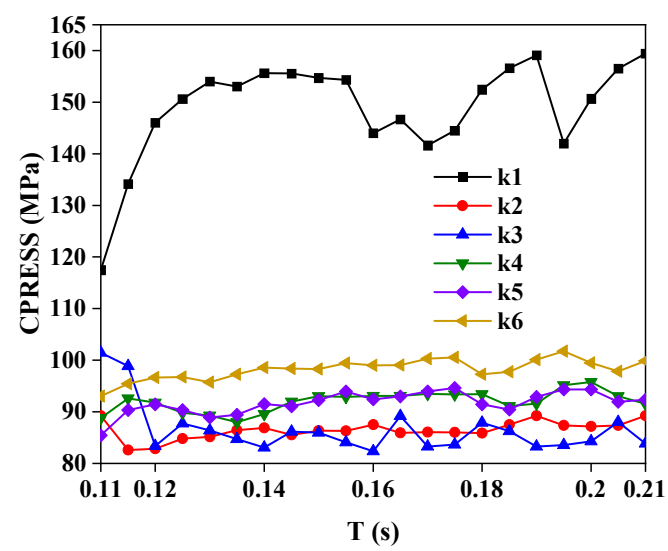

(c) 0.2

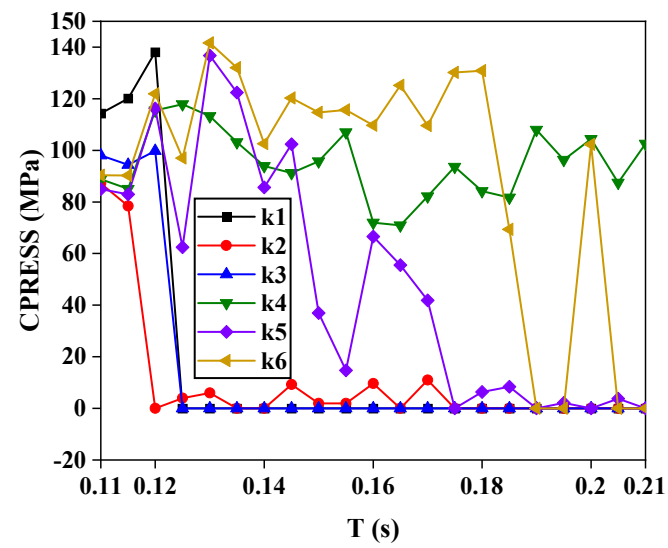

(e) 0.6

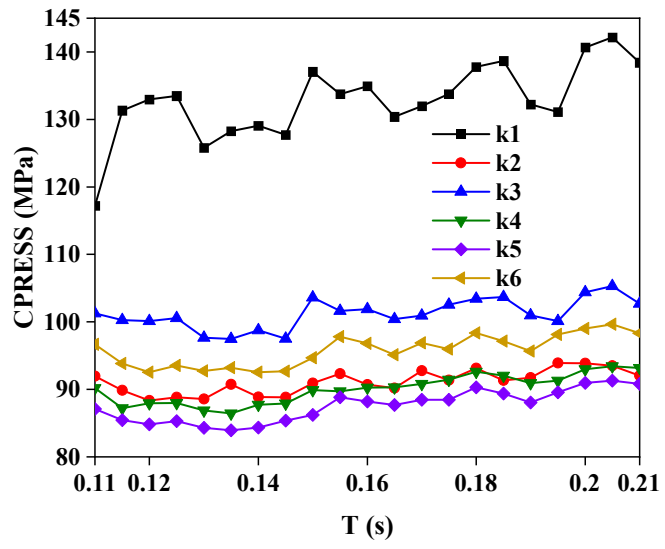

(b) 0.08

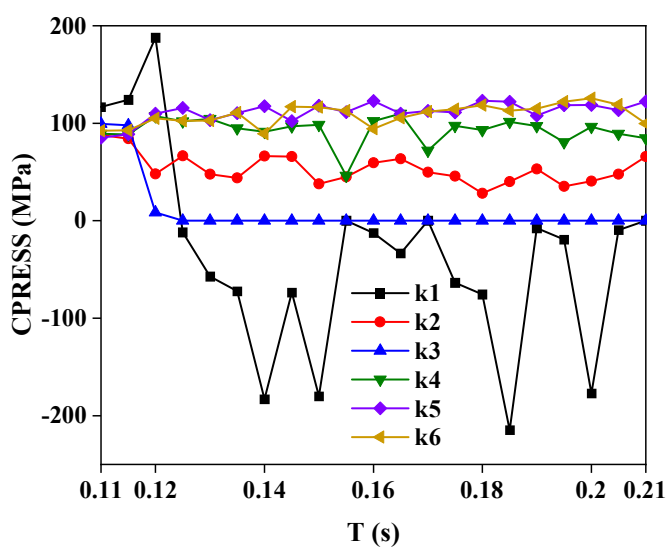

(d) 0.4

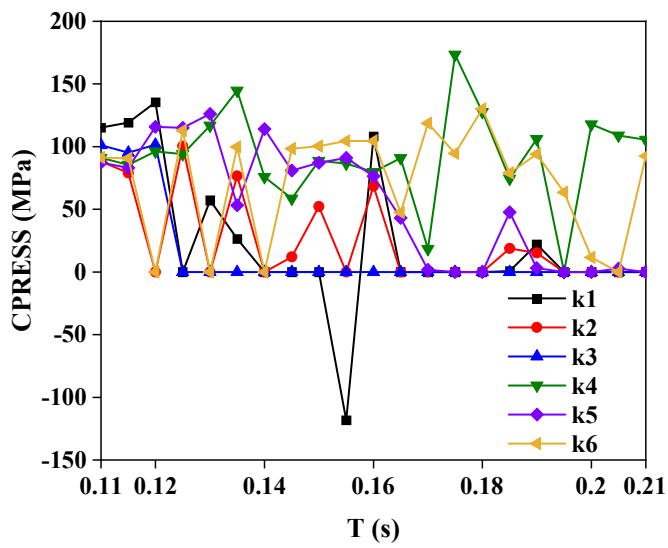

(f) 0.8

Fig. 15 After the BOP is sealed, the contact stress along the k-path between rubber core and tubing when the tubing moves under different friction coefficients 


\section{The influence of rubber core wear on sealing performance}

During the snubbing service of gas well, there is dry friction between rubber core and tubing, which can easily cause the rubber core to wear. The wear of the rubber core will greatly affect the sealing performance of the BOP (Angerhausen et al., 2019).

In order to study the influence of rubber attrition rate on the sealing performance, it is assumed that the rubber core is worn uniformly. The definition of the abrasion loss is shown in Fig. 16, where "Wear" is the abrasion loss.

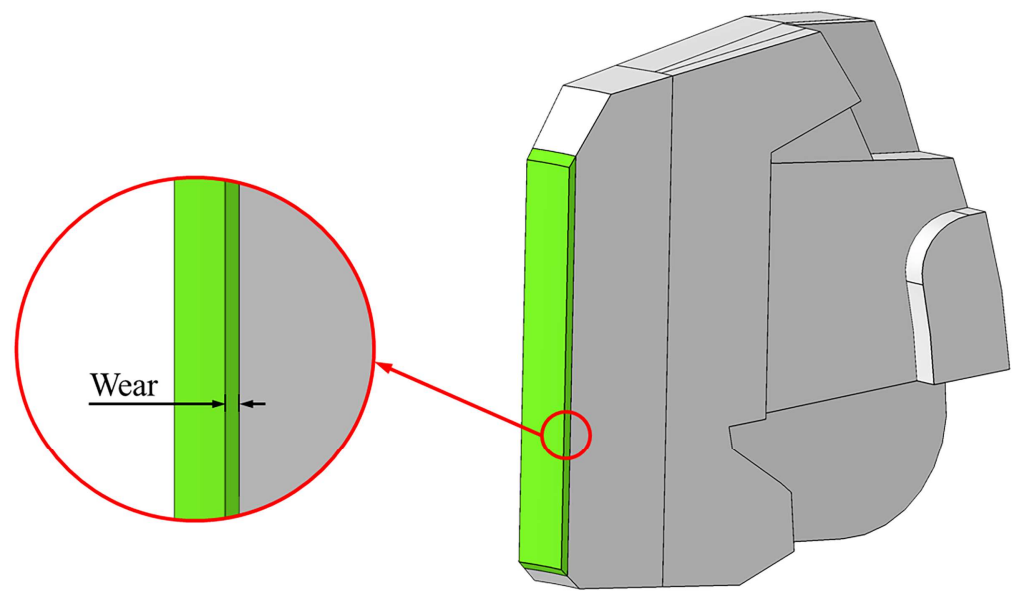

Fig. 16 Schematic diagram of rubber core wear

\subsection{Analysis of the influence of rubber abrasion on the sealing performance}

The rubber storage capacity of annular BOP has a huge impact on the sealing performance. In order to make the seal safe and reliable, the rubber core must have sufficient rubber storage and a large storage ratio (Sun and Wei, 1995).

(1) Equation for calculating rubber storage

$$
V=S \delta n,
$$

where $S$ is the cross-sectional area of rubber between two supporting bars; $\delta$ is the thickness of rubber between two supporting bars; $n$ is the number of supporting bars.

(2) Equation for calculating rubber storage ratio

$$
i=V / V_{\mathrm{A}},
$$

where $V_{\mathrm{A}}$ is the inner annular space that can be filled by the spherical rubber core.

Figure 17 shows the change of the rubber core storage ratio with abrasion rate. It can be seen that as the attrition rate increases of rubber core, the rubber core storage ratio continues to decrease. Figure 18 shows the contact stress of rubber core along the $\mathrm{K}$ path under different attrition rate when the BOP is sealed. When the attrition rate is between 2 and $10 \mathrm{~mm}$, the peak value of the contact stress changes a little, but it has a greater impact on the contact stress of the lower part of the rubber core. When the attrition rate is below $4 \mathrm{~mm}$, the contact stress is basically unchanged, which is the same as there is no wear. When the attrition rate is between 6 and $8 \mathrm{~mm}$, the contact stress of the lower part of rubber core and the tubing is lower than when the attrition rate is below $4 \mathrm{~mm}$. When the wear is $10 \mathrm{~mm}$, the contact stress drops again. Even if the attrition rate is $10 \mathrm{~mm}$, the contact stress on most areas of the contact surface between rubber core and tubing keeps above $35 \mathrm{MPa}$, and the wellhead can be sealed. This is because the rubber core of annular BOP has a sufficient rubber storage. After a part of the rubber is worn, there is still enough rubber to be squeezed out between the supporting ribs for sealing. When the attrition exceeds $10 \mathrm{~mm}$, the contact stress fluctuates greatly, sealing performance of the BOP is significantly reduced, and sealing conditions cannot be met.

As the attrition rate of rubber core increases, and piston stroke remains unchanged, the contact stress decreases 
faster in the lower part of the rubber core. When the attrition rate is high, the contact stress in some areas drops to zero quickly. The closer to the lower part of the rubber core, the faster the descending speed. This phenomenon occurs because in the process of contact between rubber core and tubing, when the piston stroke does not change, and the storage capacity of rubber core is not enough to completely compensate for the rubber in the worn part of the rubber core, the lower part of rubber core is in contact insufficient with the tubing, resulting in a situation where the contact stress is zero. Figure 19 shows the deformation of rubber core when the seal is completed under $10 \mathrm{~mm}$ wear and no wear. It can be seen from Fig. 19 that when worn by $10 \mathrm{~mm}$, the contact between rubber core and tubing is obviously not as good as when there is no wear. It is consistent with the analysis result of Fig. 18.

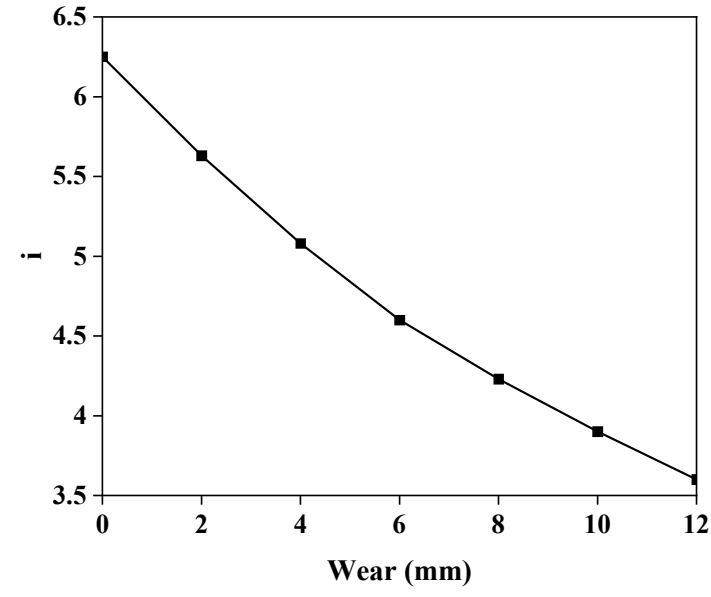

Fig. 17 The rubber storage ratio changes with the attrition rate

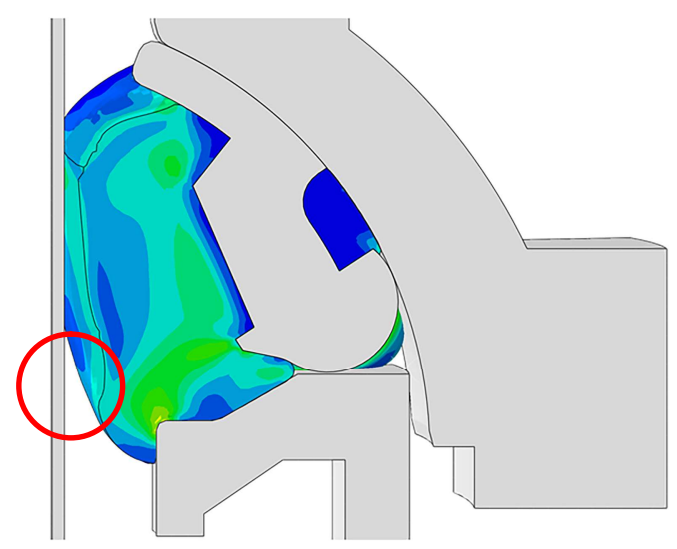

(a)

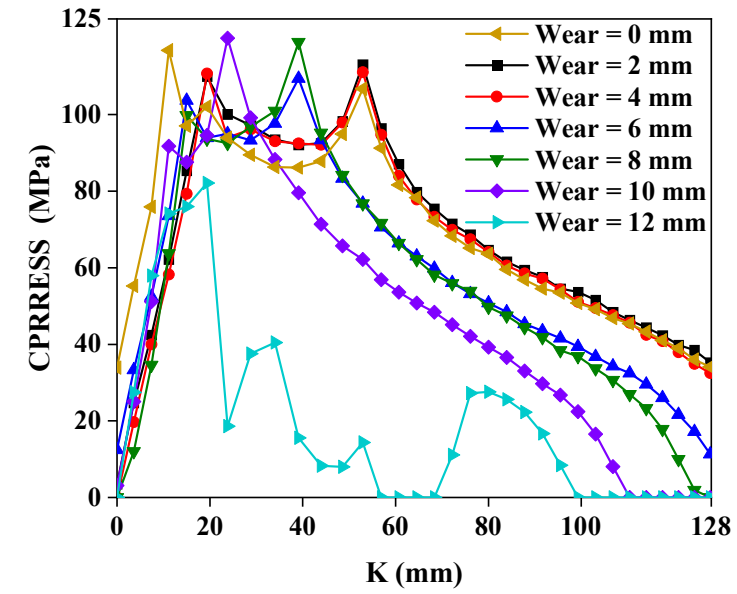

Fig. 18. The contact stress along the k-path between rubber core and tubing when the BOP seals the wellhead annulus with different rubber core attrition rate

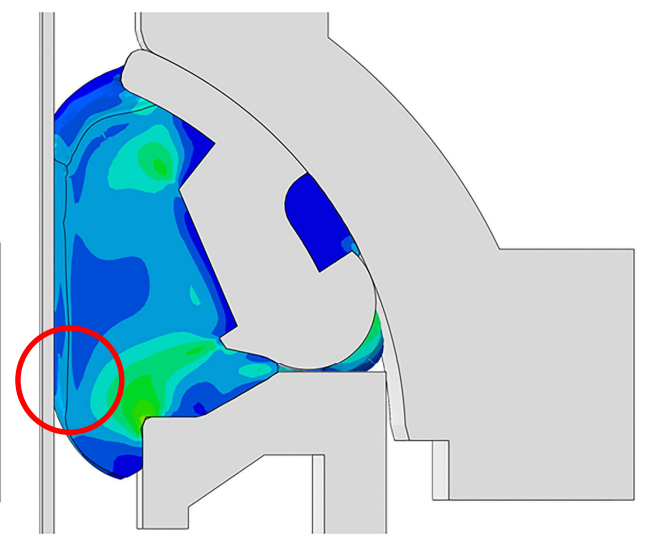

(b)

Fig. 19 The BOP is sealed under the condition of rubber core wear $10 \mathrm{~mm}$ and no wear (a) $10 \mathrm{~mm}$ (b) no

Figure 20(a) shows the contact stress of rubber core when the wear is $12 \mathrm{~mm}$. It can be seen from Fig. 20(a) that there is a zero contact stress area at the edge of the rubber core. This is because the rubber core is deformed irregularly during the piston pushing process after the rubber core is severely worn. When the piston stroke continues to increase to $83 \mathrm{~mm}$ and $86 \mathrm{~mm}$, the peak contact stress and contact area increase, but there is still a zero contact stress area at the edge of the rubber core, as shown in Fig. 20(b) and Fig. 20(c). At this time, the maximum contact stress is close to 170 $\mathrm{MPa}$, and the maximum stress of rubber core is close to $216 \mathrm{MPa}$. Further improve piston stroke will increase the stress concentration of rubber core and cause greater damage after wear. According to Fig. 17, as the wear of the rubber core increases, the rubber storage ratio of rubber core continues to decrease, and this will cause the sealing performance of BOP to decrease. Therefore, when the attrition rate is $12 \mathrm{~mm}$ and the rubber storage ratio drops to about 3.6, the sealing 
performance of rubber core drops sharply, which is no longer suitable for the snubbing service of gas well, and the rubber core needs to be replaced in time.

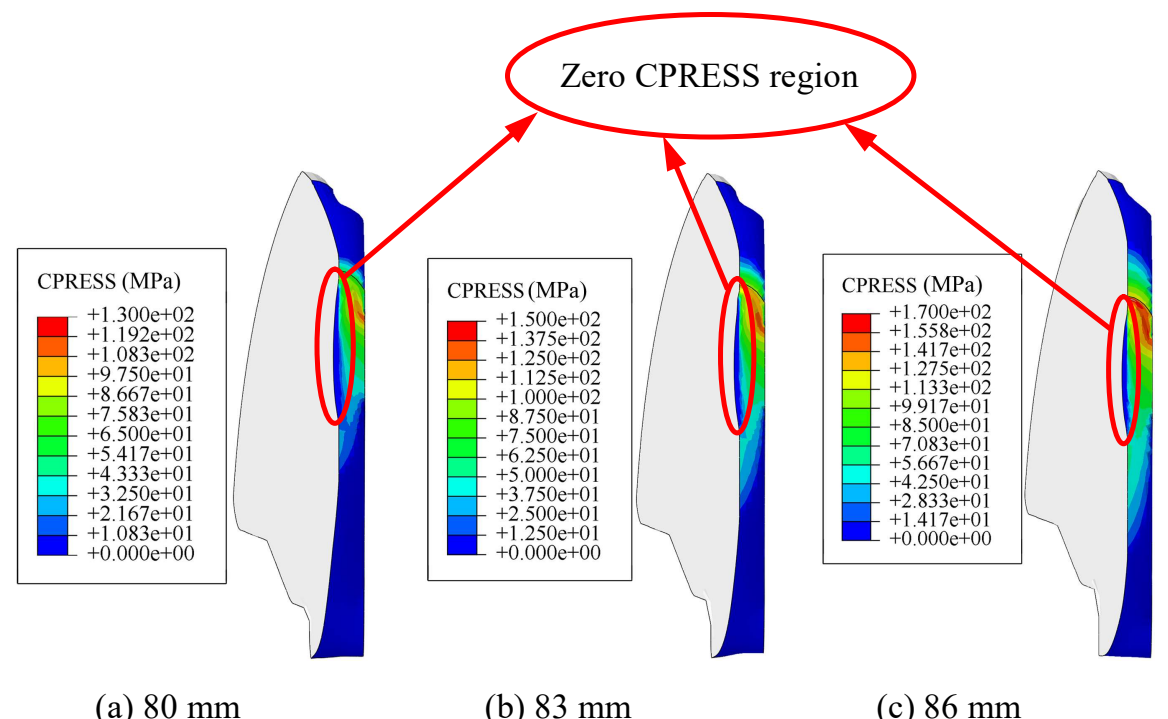

Fig. 20 The contact stress between rubber core and tubing of the sealing wellhead annulus under different piston strokes after the rubber core is worn by $12 \mathrm{~mm}$

\subsection{The influence of wear on the stress of rubber core after sealing}

Figure 21 is the maximum stress curve and the stress diagram of the deformation of rubber core when rubber core is worn and the seal is completed. It can be seen from Fig. 21 that with the increase in attrition rate, the stress of rubber core decreases when the seal is completed, with the piston stroke unchanged. The maximum stress of rubber core under $10 \mathrm{~mm}$ wear is reduced by $11.1 \%$ compared to the maximum stress of the rubber core without wear. Although the reduction in stress helps to extend the service life of the rubber core, the sealing performance of the rubber core after wear will decrease due to insufficient contact with the tubing. When the operating environment of the annular BOP is harsh and conditions in the well are complex, in order to improve the safety of the snubbing service of gas well, the piston stroke of BOP can be appropriately increased by 2 to $3 \mathrm{~mm}$ to improve the sealing performance.

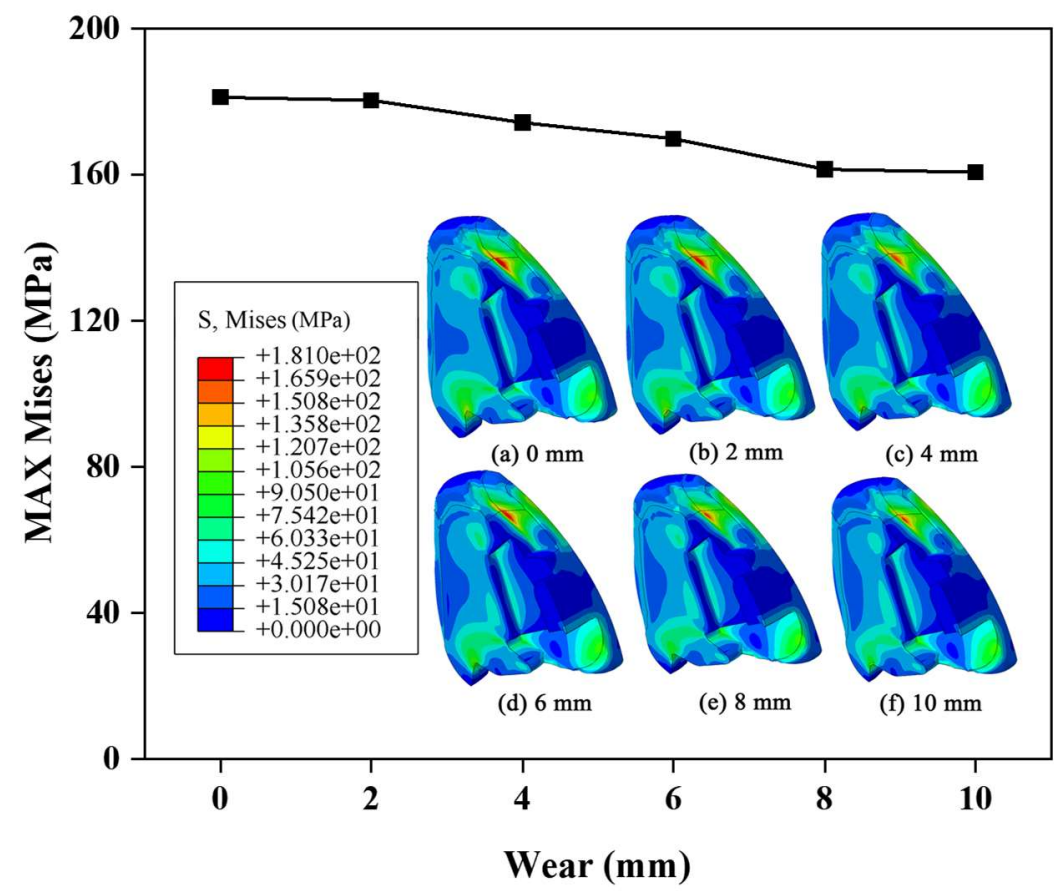

Fig. 21 Maximum stress of rubber core in sealing wellhead annulus of BOP after rubber core wear 


\section{Conclusions}

In this paper, aiming at the problem of easy to failure of the BOP rubber core in snubbing service in gas wells, by testing the Yeoh constitutive model parameters of the rubber core, and the finite element model of the BOP sealing process is further established to study the BOP sealing performance. The following conclusions were obtained.

(1) When the tubing size is $88.9 \mathrm{~mm}$, the piston stroke of $80 \mathrm{~mm}$ is more suitable for sealing. When the size of the tubing keeps unchanged, properly increasing the piston stroke by 2 to $3 \mathrm{~mm}$ will help to improve the sealing performance of BOP. However, excessive stroke will cause great damage to the spherical rubber core;

(2) The spherical rubber core annular BOP can seal the annular space formed between tubing of various sizes and the wellbore. However, the deformation of rubber core is too large while using the smaller size tubing, and it is prone to fracturing damage. By calculating the piston stroke required when the BOP seals the tubing with an outer diameter of 60 to $100 \mathrm{~mm}$, the curve is fitted and the tubing size-piston stroke correlation expression is obtained;

(3) The friction coefficient between rubber core and tubing has no significant effect on the sealing performance of BOP when the tubing is stationary. When the tubing is moving, the friction coefficient lower than 0.2 has little effect on the sealing performance of the BOP. When the friction coefficient exceeds 0.4 , the movement of the tubing will cause unstable and large fluctuations in the contact stress of rubber core, resulting in a decrease in the sealing performance of BOP;

(4) The rubber core attrition has a huge impact on the sealing performance. When the attrition rate is within $0 \sim 6$ $\mathrm{mm}$, there is no obvious influence on the sealing performance. When the attrition rate is between 6 and $10 \mathrm{~mm}$, the contact area between rubber core and tubing is reduced, but sealing can still be accomplished. When the wear is more than $10 \mathrm{~mm}$, the sealing performance of the BOP rubber core drops sharply, and it is no longer suitable for sealing the wellhead annulus.

\section{Acknowledgments}

This research was supported by Sichuan science and technology program (2019YFG0305, 2019YFG0380, 2018GZ0429, 2018CC0098, 2021ZHCG0013), China National Petroleum Corporation science and technology planning project “Gas well pressure operation technology popularization” (2020B-4121).

\section{References}

Abaqus Analysis User's Guide, Version 2016.

Angerhausen, J., Woyciniuk, M., Murrenhoff, H., Schmitz, K., 2019. Simulation and experimental validation of translational hydraulic seal wear. Tribology International.

Charlton, D.J., Yang, J., Teh, K.K., 1994. A Review of Methods to Characterize Rubber Elastic Behavior for Use in Finite Element Analysis. Rubber Chemistry and Technology 67, 481-503.

Chen, Q., Han, W., Huang, S., Li, T., Sun, Q., 2019a. Numerical simulation and experimental study of wellbore kick-control in the snubbing service(Conference Paper). Springer Series in Geomechanics and Geoengineering, 1241-1249.

Chen, T., Ma, W., Liu, S., Wu, J., 2019b. Analysis on mechanical influencing factors of fatigue behavior for the packer on pipe ram in snubbing unit. Engineering Failure Analysis 103, 20-31.

Dong, L., Li, K., Zhu, X., Li, Z., Zhang, D., Pan, Y., Chen, X., 2020. Study on high temperature sealing behavior of packer rubber tube based on thermal aging experiments. Engineering Failure Analysis 108, 104321.

Ferreira, A.J.M., Sá, J.M.A.C., Marques, A.T., 2003. Nonlinear Finite Element Analysis of Rubber Composite Shells. Strength of Materials 35, 225-235.

Fu, Y.K., Han, C.J., Wang, J., Yi, Y., 2012. Design and Analysis of Rubber Core with PTFE Ring in Ram BOP. Applied Mechanics and Materials 155-156, 686-690.

Gajewski, M., Szczerba, R., Jemioło, S., 2015. Modelling of Elastomeric Bearings with Application of Yeoh Hyperelastic Material Model. Procedia Engineering 111, 220-227.

Li, W., Tang, Y., He, Y., 2019. Simulation and experimental analysis of critical stress regions of deep-water annular 
blowout preventer. Engineering Failure Analysis 106.

Li, Z., 2015. On the Failure Modes of Spherical Rubber Core in Blowout Preventer and Measures to Improve Its Service Life. Ship \& Ocean Engineering 44, 52-55+58 (in Chinese).

Medri, G., Strozzi, A., 1984. Mechanical analysis of elastomeric seals by numerical methods. Industrial \& Engineering Chemistry Product Research and Development 23, 596-600.

Mutlu, M., Tang, Y., Franchek, M.A., Turlak, R., Gutierrez, J.A., 2018. Dynamic Performance of Annular Blowout Preventer Hydraulic Seals in Deepwater Environments. Journal of Offshore Mechanics and Arctic Engineering Vol.140 No. 6, DOI: 10.1115/1.4040391

Renaud, C., Cros, J.M., Feng, Z.Q., Yang, B., 2009. The Yeoh model applied to the modeling of large deformation contact/impact problems. International Journal of Impact Engineering 36, 659-666.

Shafiee, M., Elusakin, T., Enjema, E., 2020. Subsea blowout preventer (BOP): Design, reliability, testing, deployment, and operation and maintenance challenges. Journal of Loss Prevention in the Process Industries 66, 104170.

Skogdalen, J.E., Utne, I.B., Vinnem, J.E., 2011. Developing safety indicators for preventing offshore oil and gas deepwater drilling blowouts. Safety Science 49, 1187-1199.

Sun, Z., Wei, M., 1995. Research into Ram Rubber for 70MPa Hydraulic BOPs. China Petroleum Machinery, 9-14+61 (in Chinese).

Volokh, K.Y., 2010. On modeling failure of rubber-like materials. Mechanics Research Communications 37, $684-689$.

Volokh, K.Y., 2013. REVIEW OF THE ENERGY LIMITERS APPROACH TO MODELING FAILURE OF RUBBER. Rubber Chemistry and Technology 86, 470-487.

$\mathrm{Xu}, \mathrm{D} ., \mathrm{Wu}, \mathrm{K} ., \mathrm{Wu}, \mathrm{J} ., 2$ 2012. Analysis of Failure for Rubber Core in Spherical Blowout Preventer. Lubrication Engineering 37, 71-74 (in Chinese).

Xu, D., Yang, Y., Wu, K., 2018. Data processing method for constitutive relation of the rubber core material in spherical blowout preventer. Advances in Mechanical Engineering Vol.10.

Yao, Y., Mao, Z., Qi, Y., Pan, L., Zhang, H., Zhang, J., Yang, Y., 2019. Analysis of large deformation of sealing rubber core of air-controlled annular blowout preventer. Lubrication Engineering 44, 39-44+50.

Yeoh, O.H., 1993. Some Forms of the Strain Energy function for Rubber. Rubber Chemistry and Technology Vol.66, 754-771.

Zou, L., Yu, C., Shao, J., 2016. Finite-element Analysis of Spherical BOP in Snubbing Service of Gas Well. PROCEEDINGS OF THE 2ND INTERNATIONAL CONFERENCE ON ADVANCES IN MECHANICAL ENGINEERING AND INDUSTRIAL INFORMATICS (AMEII 2016) Vol.73, 605-608. 